\title{
The Role of Fiber Coating on SiC Fiber-Reinforced Alumina Composite
}

\author{
J. X. LI, Yohtaro MATSUO and Shiushichi KIMURA \\ Department of Inorganic Materials, Faculty of Engineering, Tokyo Institute of Technology, 2-12-1, Ookayama, Meguro-ku, Tokyo \\ $\mathrm{SiC}$ 繊維強化アルミナ複合材料における繊維コーティングの役割 \\ 李 建興・松尾陽太郎・木村脩七 \\ 東京工業大学工学部無機材料工学科, 152 東京都目黒区大岡山 2-12-1
}

[Received November 14, 1991; Accepted February 18, 1992]

\begin{abstract}
The effect of fiber coating on the residual thermal stresses, interface, and mechanical properties of CVD(C, SiC) coated Nicalon fiber-reinforced alumina matrix composite were studied. Using a tri-cylindrical model, the residual thermal stresses caused by the mismatch of their thermal expansion coefficients and the mechanical behavior were calculated. The results indicated that when the fibers coated with carbon, which has lower Young's modulus, the residual thermal stresses at fiber-coating interface and coating-matrix interface were reduced compared with uncoated fiber reinforced composite materials, and these stresses decrease with increase in the thickness of carbon coating. In the CVD- $(\mathrm{C}, \mathrm{SiC})$ coated fiber-reinforced alumina composite, the reduction of the residual interfacial stress decreased the shear strength required for fiber pullout, so that the work of fracture was increased compared with that of uncoated Nicalon fiber-reinforced alumina composite.
\end{abstract}

Key-words : Nicalon fiber, Alumina matrix, CVD-coating, Thermal stress, Bending strength, Work of fracture

\section{Introduction}

The fiber-matrix interface plays an important role in fiber-reinforced ceramic matrix composites (CMCs). With strong bonded interfaces, the composites fail catastrophically like the monolithic ceramics, but if the interface bonding is weak (or with unbonded interfaces), the toughness of CMCs can be improved by interface debonding, frictional sliding, and fiber pullout during crack propagation. However, if the interface bonding is too weak, the toughness and the strength of composites can not be improved due to fiber's free-slide through the fibermatrix interfaces. For the high performance composites, an optimal interface bonding would be expected to bring out the potential of fiber reinforcement. ${ }^{1)-2)}$

On the other hand, the tailoring of interface bonding by choosing the combination of ceramic fiber and ceramic matrix is diffcult, because the kinds of the commercially available fibers are limited. Fiber coating, which is considered to be an effective method to modify the fiber-matrix interfaces, was widely used in metal or ceramic matrix composites. ${ }^{3)-5)}$ There- fore, the fiber-matrix interfacial shear strength, which should be influenced by the interfacial bonding and the residual thermal stress, would be changed through fiber coating.

In the ceramic matrix composites, if the thermal expansion coeffcient of the fiber is lower than that of the matrix, the radial compressive stresses, which resist the interface debonding, frictional sliding, and pullout, can be induced by the matrix shrinkage during cooling from sintering temperature. However, if the thermal expansion coeffcient of the fiber is higher than that of the matrix, debonding would occur during cooling, and the fiber can be easily pullout from the matrix. The thermal stresses in long sealed elastic cylinders due to the mismatch of thermal expansion coeffcients was evaluated by Poritsky, ${ }^{6}$ ) and using this model, Chawla ${ }^{7,8)}$ estimated the thermal stresses in $\mathrm{W}$ fiber reinforced copper composites. Concerning the CMCs, the residual thermal stresses have been studied extensively,1),9)-13) because the toughness of CMCs strongly depends on the interfacial shear strength. Hsuch ${ }^{14)}$ estimated the thermal stress considering the anisotropy of thermal expansion coeffcients of the fiber in the transverse and axial direction. In his later work, ${ }^{15)}$ the effects of a film at the whisker-matrix interface on the thermal stress due to thermomechanical mismatch during cooling was considered in the case of a single whisker in an infinite matrix, and it was found that if the film has a low Young's modulus, the thermal stresses in the composites can be reduced remarkably. As mentioned above, a coating layer on the fiber surface is needed to resist the thermal degradation of the fiber and the interface reaction at elevated temperature in fiber-reinforced CMCs. However, the studies of the thermal stresses in these composites are not suffcient.

In this study, a tri-cylindrical model is introduced to elucidate the effect of fiber coating on the residual thermal stresses in fiber-reinforced ceramic composites. Furthermore, the $\mathrm{SiC}$ fibers with or without CVD- $(\mathrm{C}, \mathrm{SiC})$ coating are incorporated into an alumina matrix, and the effect of fiber coating on the mechanical properties, fracture morphologies and the fiber-matrix interface are also investigated. 


\section{Experimental procedures}

Nicalon fiber was coated with $(\mathrm{C}, \mathrm{SiC})$ at $1300^{\circ} \mathrm{C}$ by low pressure chemical vapor deposition, and a coating layer about $0.5 \mu \mathrm{m}$ was deposited on the fiber surfaces. In the previous paper ${ }^{16)}$ it was found that a carbon rich layer was deposited on the fiber surface initially, then the composition of coating layer changed to a mixture structures of $\mathrm{SiC}$ and $\mathrm{C}$. The alumina matrix composites reinforced by uncoated or $\mathrm{CVD}-(\mathrm{C}, \mathrm{SiC})$ coated Nicalon fibers were fabricated by infiltrating the fiber into alumina slurry, drying and hot-pressing. The hot-pressing was done at $1300^{\circ} \mathrm{C}$ and $30 \mathrm{MPa}$ in $\mathrm{Ar}$ atmosphere. The volume fraction of the fibers was approximately 5\%. The bulk densities were 3.87 and $3.88 \mathrm{~g} / \mathrm{cm}^{3}$ for uncoated and coated fiber-reinforced alumina matrix composites, respectively. The samples were cut into $3.4 \times 1.3 \times 20 \mathrm{~mm}$ rectangular cross-sectioned bars for three-point bending strength measurement. The lower span in bending was $16 \mathrm{~mm}$, and the crosshead speed was $0.1 \mathrm{~mm} / \mathrm{min}$.

3. The effect of fiber coating on the residual thermal stresses of ceramic matrix composites -a tri-cylindrical model-

In order to fabricate the CMCs, an elevated temperature processing is necessary to complete the sintering. At such higher temperature, diffusion and viscous (or plastic) flow in the matrix will occur to relax the stresses, but the thermal stresses will be generated in both the fiber and the matrix because of the thermomechanical mismatch between two components during cooling. A composite cylindrical model is usually applied to simplify the stress analysis in the unidirectional fiber-reinforced composite materials. ${ }^{7), 8), 14)}$

In this paper, by assuming that the stress is free at sintering temperature and that there is no interaction of the stress field between the fibers, a tri-cylindrical model is introduced to analyse the residual thermal stresses of coated fiber-reinforced ceramic matrix composites (Fig. 1). If the slips do not take place at fiber-coating interface and coating-matrix interface during cooling from sintering temperature, the following conditions must be satisfied.

$$
\begin{aligned}
& \varepsilon_{\theta \mathrm{f}}=\varepsilon_{\theta \mathrm{c}}(\text { at the fiber-coating interface }) \\
& \varepsilon_{\theta \mathrm{c}}=\varepsilon_{\theta \mathrm{m}} \quad(\text { at the coating-matrix interface) } \\
& \varepsilon_{\mathrm{zf}}=\varepsilon_{\mathrm{zc}}=\varepsilon_{\mathrm{zm}} \\
& \sigma_{\mathrm{zf}}+\frac{c^{2}-a^{2}}{a^{2}} \sigma_{\mathrm{zc}}+\frac{b^{2}-c^{2}}{a^{2}} \sigma_{\mathrm{zm}}=0
\end{aligned}
$$

where $a, b$ and $c$ are the radii of the fiber, matrix and coating, $\sigma_{\theta}$ and $\sigma_{z}$ are the tangential and axial stresses; $\varepsilon_{\theta}$ and $\varepsilon_{z}$ are the tangential and axial strains, respectively. The subscripts $f, c$ and $m$ denote the fiber, coating and matrix.

When the temperature is changed from the sinter-

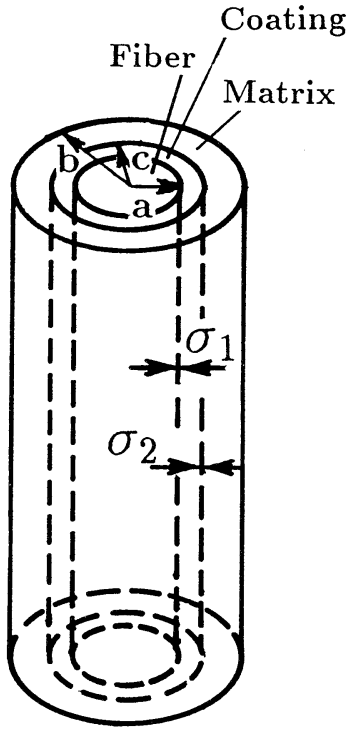

Fig. 1. Schematic showing of a composite tri-cylindrical model (a coated fiber embedded in a matrix).

ing temperature to room temperature (the difference of temperature is $\Delta T$ ), the strains which consist of thermal strains and elastic strains within the components of the fiber, coating and matrix can be expressed as follows:

$$
\begin{aligned}
& \varepsilon_{\theta \mathrm{m}}=\frac{1}{E_{\mathrm{m}}}\left[\sigma_{\theta \mathrm{m}}-v_{\mathrm{m}}\left(\sigma_{\mathrm{rm}}+\sigma_{\mathrm{zm}}\right)\right]+\alpha_{\mathrm{m}} \Delta T \\
& \varepsilon_{\theta \mathrm{c}}=\frac{1}{E_{\mathrm{c}}}\left[\sigma_{\theta \mathrm{c}}-v_{\mathrm{c}}\left(\sigma_{\mathrm{rc}}+\sigma_{\mathrm{zc}}\right)\right]+\alpha_{\mathrm{c}} \Delta T \\
& \varepsilon_{\theta \mathrm{f}}=\frac{1}{E_{\mathrm{f}}}\left[\sigma_{\theta \mathrm{f}}-v_{\mathrm{f}}\left(\sigma_{\mathrm{rf}}+\sigma_{\mathrm{zf}}\right)\right]+\alpha_{\mathrm{f}} \Delta T \\
& \varepsilon_{\mathrm{zm}}=\frac{1}{E_{\mathrm{m}}}\left[\sigma_{\mathrm{zm}}-v_{\mathrm{m}}\left(\sigma_{\mathrm{rm}}+\sigma_{\theta \mathrm{m}}\right)\right]+\alpha_{\mathrm{m}} \Delta T \\
& \varepsilon_{\mathrm{zc}}=\frac{1}{E_{\mathrm{c}}}\left[\sigma_{\mathrm{zc}}-v_{\mathrm{c}}\left(\sigma_{\mathrm{rc}}+\sigma_{\theta \mathrm{c}}\right)\right]+\alpha_{\mathrm{c}} \Delta T \\
& \varepsilon_{\mathrm{zf}}=\frac{1}{E_{\mathrm{f}}}\left[\sigma_{\mathrm{zf}}-v_{\mathrm{f}}\left(\sigma_{\mathrm{rf}}+\sigma_{\theta \mathrm{f}}\right)\right]+\alpha_{\mathrm{f}} \Delta T
\end{aligned}
$$

where $\alpha$ is the thermal expansion coeffcient, $E$ is Young's modulus and $v$ is Poisson's ratio, respectively. In general, the thermal expansion coeffcient of the fiber is lower than that of the matrix in the CMCs and then the thermomechanical mismatch may cause the radial compressive stresses at fiber and coating layer. The radial and tangential stresses in the fiber, coating and matrix are given as:

$$
\begin{aligned}
& \text { at the fiber } \quad \sigma_{\mathrm{rf}}=\sigma_{\theta \mathrm{f}}=\sigma_{1} \\
& \text { at the coating } \\
& \qquad \sigma_{\mathrm{rc}}=\frac{c^{2} \sigma_{2}-a^{2} \sigma_{1}}{c^{2}-a^{2}}+\frac{a^{2} c^{2}\left(\sigma_{1}-\sigma_{2}\right)}{\left(c^{2}-a^{2}\right) r^{2}} \\
& \sigma_{\theta \mathrm{c}}=\frac{c^{2} \sigma_{2}-a^{2} \sigma_{1}}{c^{2}-a^{2}}-\frac{a^{2} c^{2}\left(\sigma_{1}-\sigma_{2}\right)}{\left(c^{2}-a^{2}\right) r^{2}}
\end{aligned}
$$


at the matrix

$$
\begin{aligned}
& \sigma_{\mathrm{rm}}=\sigma_{2} \frac{c^{2}\left(b^{2}-r^{2}\right)}{r^{2}\left(b^{2}-c^{2}\right)} \\
& \sigma_{\theta \mathrm{m}}=-\sigma_{2} \frac{c^{2}\left(b^{2}+r^{2}\right)}{r^{2}\left(b^{2}-c^{2}\right)}
\end{aligned}
$$

where $\sigma_{1}$ and $\sigma_{2}$ are the radial stresses at interfaces of fiber-coating and coating-matrix. From Eqs. (1) to $(3)$, the following relations with respect to $\sigma_{\mathrm{zf}}, \sigma_{\mathrm{zc}}$, $\sigma_{\mathrm{zm}}, \sigma_{1}$ and $\sigma_{2}$ are obtained.

$$
\begin{aligned}
& \frac{v_{\mathrm{c}}}{E_{\mathrm{c}}} \sigma_{\mathrm{zc}}-\frac{v_{\mathrm{f}}}{E_{\mathrm{f}}} \sigma_{\mathrm{zf}}+\left[\frac{1-v_{\mathrm{f}}}{E_{\mathrm{f}}}+\frac{c^{2}+a^{2}}{E_{\mathrm{c}}\left(c^{2}-a^{2}\right)}+\frac{v_{\mathrm{c}}}{E_{\mathrm{c}}}\right] \sigma_{1} \\
& -\frac{2 c^{2}}{E_{\mathrm{c}}\left(c^{2}-a^{2}\right)} \sigma_{2}=\left(\alpha_{\mathrm{c}}-\alpha_{\mathrm{f}}\right) \Delta T \\
& \frac{v_{\mathrm{m}}}{E_{\mathrm{m}}} \sigma_{\mathrm{zm}}-\frac{v_{\mathrm{c}}}{E_{\mathrm{c}}} \sigma_{\mathrm{zc}}-\frac{2 a^{2}}{E_{\mathrm{c}}\left(c^{2}-a^{2}\right)} \sigma_{1}+\left[\frac{c^{2}+a^{2}}{E_{\mathrm{c}}\left(c^{2}-a^{2}\right)}\right. \\
& \left.\quad+\frac{b^{2}+c^{2}}{E_{\mathrm{m}}\left(b^{2}-c^{2}\right)}-\frac{v_{\mathrm{c}}}{E_{\mathrm{c}}}+\frac{v_{\mathrm{m}}}{E_{\mathrm{m}}}\right] \sigma_{2}=\left(\alpha_{\mathrm{m}}-\alpha_{\mathrm{c}}\right) \Delta T \\
& \frac{1}{E_{\mathrm{c}}} \sigma_{\mathrm{zc}}-\frac{1}{E_{\mathrm{f}}} \sigma_{\mathrm{zf}}+2\left(\frac{v_{\mathrm{c}}}{E_{\mathrm{c}}} \frac{a^{2}}{c^{2}-a^{2}}+\frac{v_{\mathrm{f}}}{E_{\mathrm{f}}}\right) \sigma_{1} \\
& \quad-2 \frac{v_{\mathrm{c}}}{E_{\mathrm{c}}} \frac{c^{2}}{c^{2}-a^{2}} \sigma_{2}=\left(\alpha_{\mathrm{f}}-\alpha_{\mathrm{c}}\right) \Delta T \\
& \frac{1}{E_{\mathrm{m}}} \sigma_{z \mathrm{~m}}-\frac{1}{E_{\mathrm{f}}} \sigma_{\mathrm{zf}}+2 \frac{v_{\mathrm{f}}}{E_{\mathrm{f}}} \sigma_{1} \\
& \quad+2 \frac{v_{\mathrm{m}}}{E_{\mathrm{m}}} \frac{c^{2}}{b^{2}-c^{2}} \sigma_{2}=\left(\alpha_{\mathrm{f}}-\alpha_{\mathrm{m}}\right) \Delta T \\
& \sigma_{\mathrm{zf}}+\frac{c^{2}-a^{2}}{a^{2}} \sigma_{\mathrm{zc}}+\frac{b^{2}-c^{2}}{a^{2}} \sigma_{\mathrm{zm}}=0
\end{aligned}
$$

As shown in Eq. (4), the residual thermal stresses are affected by the thermomechanical properties and the thickness of the coating layer as well as the volume fraction of the fibers and the thermomechanical mismatch between the fiber and the matrix. For the coated Nicalon fiber-reinforced alumina matrix composites, the residual thermal stresses can be calculated by substituting the values of the thermomechanical properties of the fiber, coating and matrix (Table 1) into Eq. (4). To simplify the argument in this paper, the stress analysis is based on the assumption that Nicalon fibers were coated with the pure $\mathrm{C}$ or pure $\mathrm{SiC}$. Figure 2 shows the axial stresses within the matrix as a function of the coating thick-

Table 1. The thermomechanical properties of the fiber, coating and matrix.

\begin{tabular}{lclc} 
& $E(\mathrm{GPa})$ & $\nu$ & $\alpha\left(1 /{ }^{\circ} \mathrm{C}\right)$ \\
Nicalon fiber & 200 & 0.25 & $3 \times 10^{-6}$ \\
Sic-coating & 480 & 0.19 & $4.8 \times 10^{-6}$ \\
C-coating & 10 & 0.15 & $1.5 \times 10^{-6}$ \\
$\mathrm{Al}_{2} \mathrm{O}_{3}$ matrix & 400 & 0.22 & $8 \times 10^{-6}$ \\
\hline
\end{tabular}

ness and the volume fraction of the fibers in the $\mathrm{C}$ coated and $\mathrm{SiC}$ coated Nicalon fiber-reinforced alumina matrix composites. Since the thermal expansion coeffcient of Nicalon fiber is much less than that of the alumina matrix, the tensile axial stress is generated within the matrix. The residual tensile stresses increase as the volume fraction of the fibers increases, and cracks will be generated within the matrix normal to the fiber axis when the residual stress reaches a critical value. As shown in Fig. 2, with respect to the fiber with $\mathrm{C}$ coating, there is only a small change in residual stress, $\sigma_{z \mathrm{~m}}$. On the contrary, for the fiber with $\mathrm{SiC}$ coating, $\sigma_{\mathrm{zm}}$ increases as the coating thickness increases.

The radial stress $\sigma_{2}$ at coating-matrix interface is illustrated in Fig. 3 as a function of the coating thickness and the volume fraction of the fibers. The radial stress at fiber-coating interface is almost the same with $\sigma_{2}$. For the Nicalon fiber-reinforced alumina matrix composite, the fiber pullout affected by the radial interfacial stresses may easily be conducted in the case of the higher volume fraction of the fibers, since it has a lower interfacial stress. As shown in

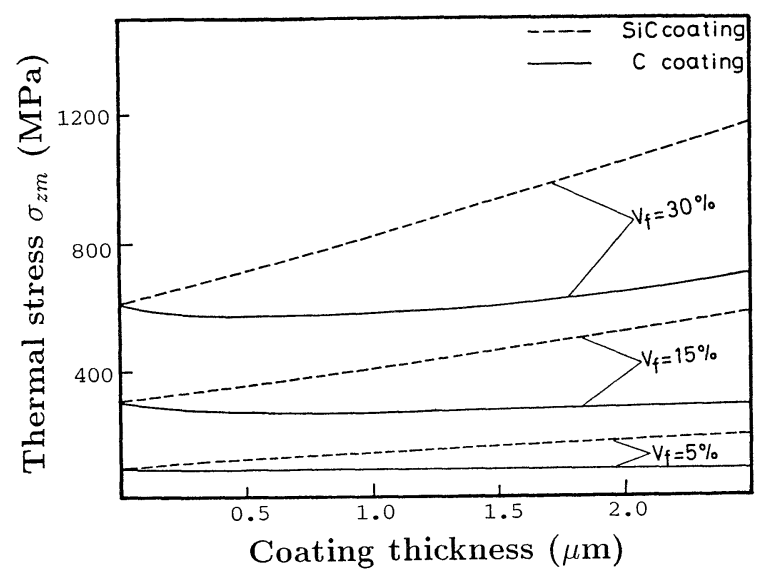

Fig. 2. Residual axial stress within alumina matrix as a function of the coating thickness.

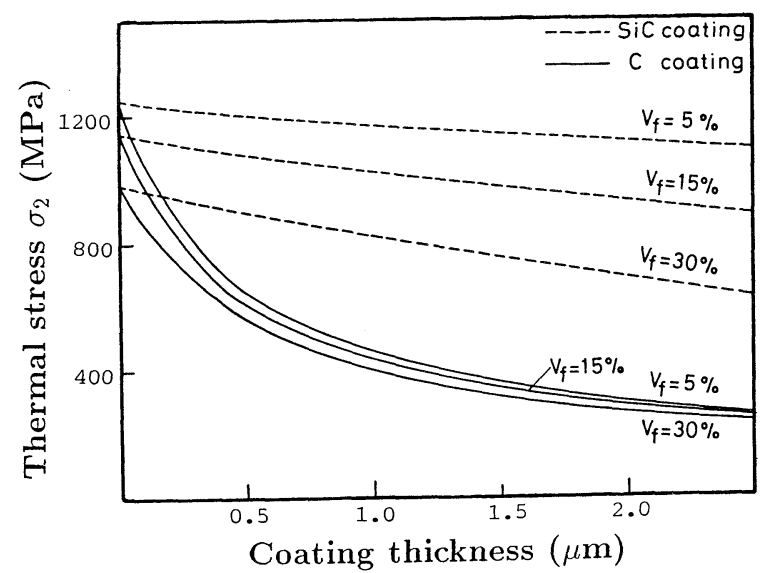

Fig. 3. Residual interfacial stress at coating-matrix interface as a function of the coating thickness. 
Fig. 3, the interfacial stress $\sigma_{2}$ is reduced by fiber coating, and a coating with lower Young's modulus is more effective in reducing the thermal stresses. When Nicalon fibers coated by $\mathrm{C}$ with thickness about $0.5 \mu \mathrm{m}$, the interfacial stress is reduced to half in comparing with uncoated fibers. It is evident from above discussions that the interfacial stresses of composites can be tailored by choosing the compositions, structures and thickness of coating.

\section{Bending fracture of CVD- (C, SiC) coated} fiber-reinforced alumina matrix composite

Mechanical testing of the Nicalon fiber-reinforced composite was performed in three-point bending mode. The load-time curves were obtained at room temperature for uncoated and coated fiber-reinforced alumina matrix composites as shown in Fig. 4. The strengths of uncoated and coated fiber-reinforced alumina composites were $430 \mathrm{MPa}$ and 405 $\mathrm{MPa}$, respectively. The load-time curves are linear up to the maximum load for both samples. However, since the volume fraction of the fibers is lower, the fibers were unable to sustain the additional load increment after the first matrix cracking ${ }^{17)}$ which corresponds to the maximum load in the figures. Therefore, a sudden load drop occurred in both cases. The magnitude of load drop was different each other as shown in Fig. 4. After sudden load drop, the load nonlinearlity increases up to the second peak, and then gradually decrease again. It is evident that the debonding of the fiber-matrix interfaces (or fibercoating interface and coating-matrix interface in
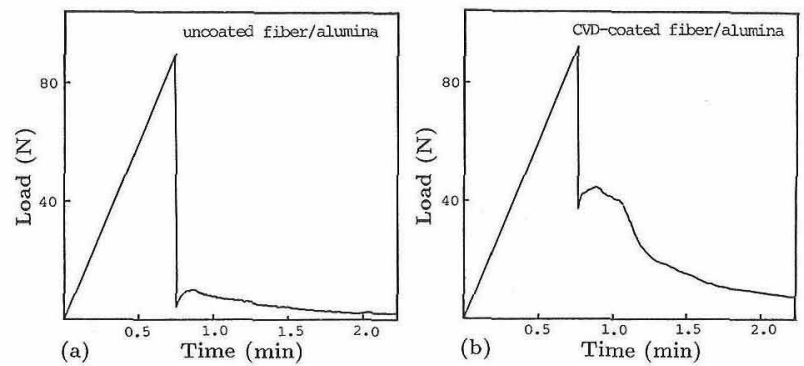

Fig. 4. The load-time curves measured from bending test for (a) uncoated and (b) coated fiber-reinforced alumina matrix composites.

coated fiber reinforced alumina composites) occurred from the initial part of non-linear stage, and the interfaces were entirely debonded at the second peak of the load. After this point, the load was dependent on the fractional sliding and the pullout of the fibers. Therefore, the work of fracture affected by the area of non-linear part of the coated fiber-reinforced composite is higher than the uncoated fiberreinforced composite. Figure 5 shows the fracture surfaces of uncoated and coated fiber-reinforced composites. The fiber pullouts are hardly observed due to the higher residual compressive stress at fiber-marix interface in uncoated fiber-reinforced composite. However, in the case of coated fibers, the fiber pullouts from the matrix are remarkable (Fig. 5(b)), since the radial compressive stresses at interfaces were reduced by the CVD- $(\mathrm{C}, \mathrm{SiC})$ coating. The modes of fiber pullout in coated fiber-reinforced composite are shown in Fig. 6 . Since the fiber pullouts oc-
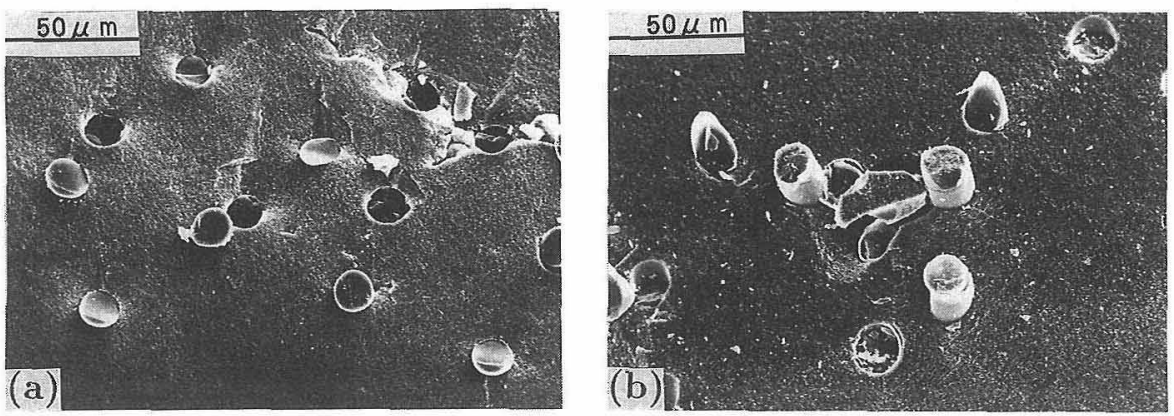

Fig. 5. Fracture surfaces of (a) uncoated and (b) coated fiber-reinforced alumina matrix composites.
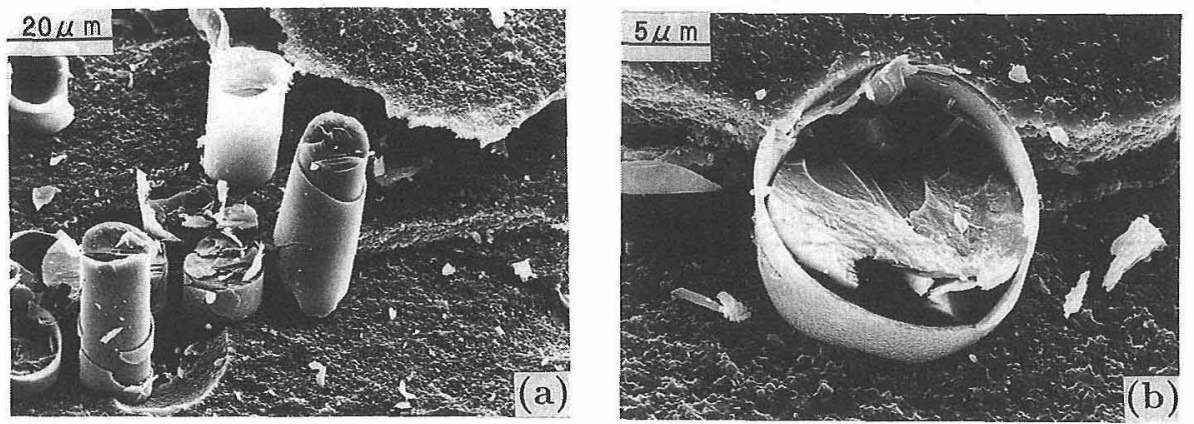

Fig. 6. Fracture surfaces of coated fiber-reinforced alumina matrix composite; (a) showing the fiber pullouts and (b) showing a crack-branching during the fiber failure. 
curred at both the fiber-coating interface and coating-matrix interface (Fig. 6(a)), it can be considered that the bonding strengths at both interfaces are weak. The fracture surface of coated fiber shows a glass-like brittle failure and a crack-branching is seen as shown in Fig. 6(b).

\section{Conclusions}

In this work, a tri-cylindrical composite model was introduced to calculate the residual thermal stresses in the coated fiber-reinforced ceramic matrix composites, and by incorporating the CVD- $(\mathrm{C}, \mathrm{SiC})$ coated Nicalon fibers to an alumina matrix, the effect of the coating on interfaces was investigated. It is found that the interfacial stresses, which are influenced by the interfacial bonding and the residual thermal stresses, can be controlled by choosing the thermomechanical properties and the thickness of the fiber coating. If fiber is coated with carbon, which has lower value of Young's modulus, the residual interfacial stresses can be decreased with increase of the carbon coating thickness. In the case of Nicalon fiber with $(\mathrm{C}, \mathrm{SiC})$ coating, since the residual interfacial stresses are reduced by the fiber coating, the fiber can easily be pullout from the alumina matrix, and the work of fracture is higher in CVD- $(\mathrm{C}, \mathrm{SiC})$ coated fiber-reinforced alumina composite compared with uncoated one. It is evident that to improve the fracture toughness and the thermal stability of
CMCs, a pertinent fiber coating like CVD- $(\mathrm{C}, \mathrm{SiC})$ is needed.

\section{References}

1) B. Budiansky, J. W. Hutchinson and A. G. Evans, J. Mech. Phys. Solids, 34, 167-89 (1986).

2) D. B. Marshall and A. G. Evans, J. Am. Ceram. Soc., 68, 225-31 (1985)

3) J. Avenston, Nature, 226, 146-47 (1970).

4) R. N. Singh and M. K. Brun, Ceram. Eng. Sci. Proc., 8, 63643(1987).

5) A. J. Caputo, D. P. Stinton, R. A. Lowden and T. M. Besmann, Am. Ceram. Soc. Bull., 66, 368-72 (1987).

6) H. Poritsky, Physics, 5, 406-11 (1934).

7) K. K. Chawla, Philos. Mag., 28, 401-13 (1973).

8) K. K. Chawla, Metallography, 6, 155-69 (1973).

9) S. Majumdar, D. Kupperman and J. Singh, J. Am. Ceram. Soc., 71, 858-63 (1988).

10) C. H. Hsueh, ibid., 71, C442-44 (1988).

11) M. K. Brun and R. N. Singh, Adv. Ceram. Mater., 3, 506-09 (1988).

12) S. Majumdar and D. Kupperman, J. Am. Ceram. Soc., 72, 312-13 (1989).

13) P. G. Charalambides, ibid., 73, 1674-80 (1990).

14) C. H. Hsueh and P. F. Becher, ibid., 71, C438-41 (1988).

15) C. H. Hsueh, P. F. Becher and P. Angelini, ibid., 929-33 (1988).

16) J. X. Li, Y. Matsuo and S. Kimura, Seramikkusu Ronbunshi (J. Ceram. Soc. Japan), 99, 1129-34 (1991).

17) J. Aveston, G.A. Cooper and A.Kelly, in the Properties of Fiber Composites, Conference Proceedings of the National Physical Laboratory, IPC Science and Technology Press, Surrey, England, U. K. (1971) pp. 15-26. 